\title{
HISTOLOGICAL SPECTRUM OF CENTRAL NERVOUS SYSTEM TUMOURS- A STUDY AT A TERTIARY CARE CENTRE IN BIHAR
}

\author{
1 Associate Professor, Department of Pathology, IGIMS, Patna. \\ ${ }^{2}$ Associate Professor, Department of Pathology, IGIMS, Patna. \\ 3 Senior Resident, Department of Pathology, IGIMS, Patna. \\ 4 Senior Consultant Neurosurgeon, CNS Hospital, Patna. \\ 5 Senior Consultant Radiologist, CNS Hospital, Patna. \\ ${ }^{6}$ Associate Professor, Department of Biochemistry, IGIMS, Patna. \\ ${ }^{7}$ Senior Resident, Department of Pathology, IGIMS, Patna.
}

Anju Singh ${ }^{1}$, Reecha Singh 2 , Monalisa ${ }^{3}$, Anuj K. Singh ${ }^{4}$, Arika Singh 5 , S. S. Haque ${ }^{6}$, Amod Kumar ${ }^{7}$

\section{ABSTRACT}

\section{BACKGROUND}

Central nervous system (CNS) tumours comprise 2-5\% of all tumours in the body. Incidence of CNS tumours varies within different age groups. The aim of this article is to give an overview of the burden of CNS tumours in different age groups in our region and to study the major histologic subtypes of brain tumours.

\section{MATERIALS AND METHODS}

This study was done at CNS Hospital, Patna and Indira Gandhi Institute of Medical Sciences (IGIMS), Patna from March 2008 to July 2014.

\section{RESULTS}

Total 394 patients between 2-80 years of age with histologically confirmed CNS tumours were included in this study. Commonest tumour was glioma accounting for $44.7 \%$ of all tumours followed by meningioma (25.8\%). Metastatic tumours constituted $5.1 \%$ of all operated tumours.

\section{CONCLUSION}

This study will help to evaluate the epidemiological and pathological characteristics of the tumour and to identify various genetic and environmental factors responsible for them.

\section{KEYWORDS}

CNS Tumour, Meningioma, Glioblastoma.

HOW TO CITE THIS ARTICLE: Singh A, Singh R, Monalisa, et al. Histological spectrum of central nervous system tumours- A study at a tertiary care centre in Bihar. J. Evolution Med. Dent. Sci. 2017;6(18):1421-1424, DOI: 10.14260/Jemds/2017/311

\section{BACKGROUND}

CNS tumours comprise $2 \%$ to $5 \%$ of all tumours. Almost $88 \%$ of all CNS tumours occur in brain and the rest involve spinal cord. ${ }^{1}$ Brain tumours cause approximately $2 \%$ of all cancer deaths. $60-80 \%$ of brain tumours are primary and rest 20 $40 \%$ are metastatic. ${ }^{2}$ Despite their high degree of lethality and inescapable traumatic impact, brain tumours rarely metastasise beyond the central nervous system. Tumours of the CNS account for as many as $20 \%$ of all cancers of childhood and are second only to leukaemia as a cause of death from malignancy. In childhood, $70 \%$ of primary brain tumours are infratentorial and involve cerebellum, midbrain, pons and medulla. ${ }^{3}$

Financial or Other, Competing Interest: None.

Submission 10-01-2017, Peer Review 15-02-2017,

Acceptance 21-02-2017, Published 02-03-2017.

Corresponding Author:

Dr. Anju Singh,

Associate Professor,

Department of Pathology,

IGIMS, Patna-14.

E-mail: anju71@gmail.com

DOI: $10.14260 /$ jemds $/ 2017 / 311$
Primary brain tumours are more common in children than metastatic tumours and the most frequent among them are pilocytic astrocytoma and medulloblastoma. Most brain tumours in adults are supratentorial and arise in cerebrum. Metastatic brain tumours outnumber primary but are less frequently subjected to biopsy. Among primary brain tumours, the most common are glioma and meningioma. Most common primary tumours of spinal cord are schwannoma, meningioma and ependymoma. Exposure to high dose of ionising radiation from x-rays or radiation therapy has been the only factor consistently related to the development of brain tumours. ${ }^{4}$ The results of studies on other potential risk factors, such as occupational exposures, electromagnetic fields, pesticides, cellular phones, head trauma and n-nitroso compounds (nitrosamine, nitrosamide, nitrite, nitrate, or aspartame consumption) were inconclusive. ${ }^{5}$

The aim of this article is to give an overview of the burden of CNS tumours in different age groups in our region and to study the major histologic subtypes of brain tumours.

\section{MATERIALS AND METHODS}

We collected data from two hospitals of Patna- CNS Hospital and Indira Gandhi Institute of Medical Sciences (IGIMS), Patna. CNS Hospital in Patna is a premier hospital that deals 
mainly with cases of neurosurgery and neurology and IGIMS is a multi-super-speciality government hospital with regional cancer centre. These two hospitals provide service to patients from Bihar, Jharkhand, adjoining parts of Bengal, Assam and other north eastern states of India. Data were collected from March 2008 to July 2014 and included all the patients with a clinical and radiological suspicion of CNS tumours undergoing biopsy or resection as a part of their diagnostic or therapeutic evaluation. Haematoxylin and Eosin (H\&E) stained sections were studied and special stains and immunohistochemistry were selectively used. A predesigned data collection sheet was used for each patient and information regarding age, sex, religious background and other investigations done were recorded. All tumours covered by World Health Organisation (WHO) classification scheme were included. Childhood tumours were defined as those tumours which were diagnosed in patients less than 15 years of age.

\section{RESULTS}

Our study included 394 patients with a clinical and radiological diagnosis of CNS tumours. Patients included 260 males (66\%) and 134 females (34\%). Most common tumour group was glioma (44.7\%) followed by meningioma (26.4\%). Glioblastoma multiforme (GBM) composed $53.4 \%$ of all gliomas and $23.8 \%$ of all operated tumours. In order of decreasing frequency, other tumour types were schwannoma (7.6\%), oligodendroglial tumours (5.5\%), metastatic tumours (5\%), neurofibroma (4\%), ependymoma (3.5\%), embryonal tumours (3\%), and malignant lymphoma (3\%). Childhood tumours constituted a small group of 11 cases in our series (5.6\%). Among them, commonest was medulloblastoma (36\%), followed by ependymoma (27\%) and astrocytoma (27\%). Among astrocytoma, two cases were of diffuse astrocytoma and one was anaplastic astrocytoma. One case of glioblastoma was also found. All cases of medulloblastoma were male. (Table 1). In rest of the paediatric cases also, male preponderance was noted. Patient's age ranged between 2 to 82 years. Overall, peak incidence of tumours was seen in the age group between $46-60$ years, followed by $31-45$ years. In males, peak age group was $45-60$ years (38\% of cases) whereas in females, maximum tumours occurred between 36-50 years of age (39\% of cases) (Fig. 1). Regarding sex preponderance among adult patients, $71.4 \%$ of all astrocytic tumours, $74 \%$ of all GBM and all oligodendroglioma were male patients. Malignant lymphoma and metastatic carcinoma also showed male predominance. Neurofibroma occurred with equal frequency in males and females. Meningioma was seen more frequently in females (54\%) as compared to males. All patients of anaplastic meningioma were female. (Fig. 2)

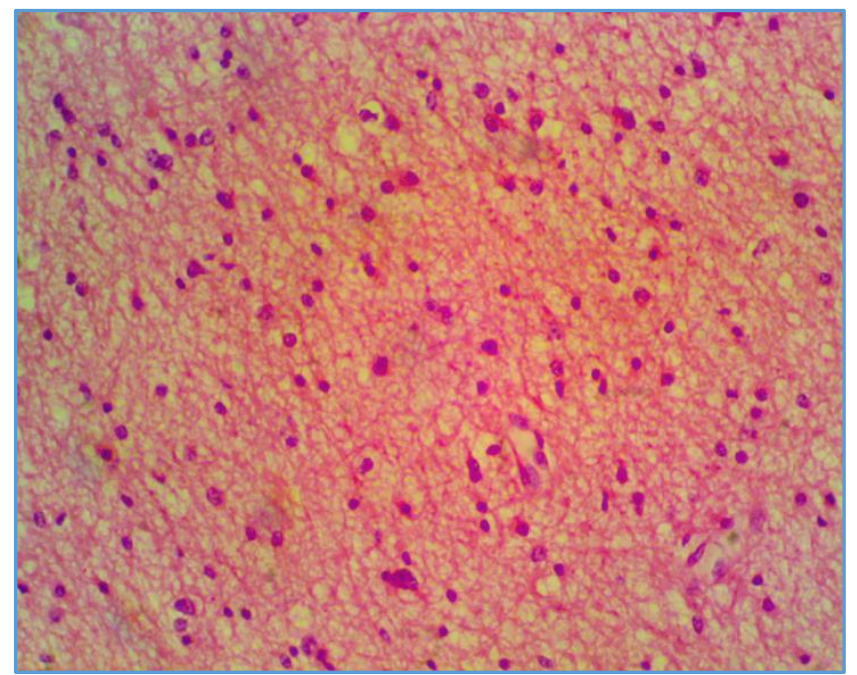

Figure 1. Astrocytoma (H\&E stain)

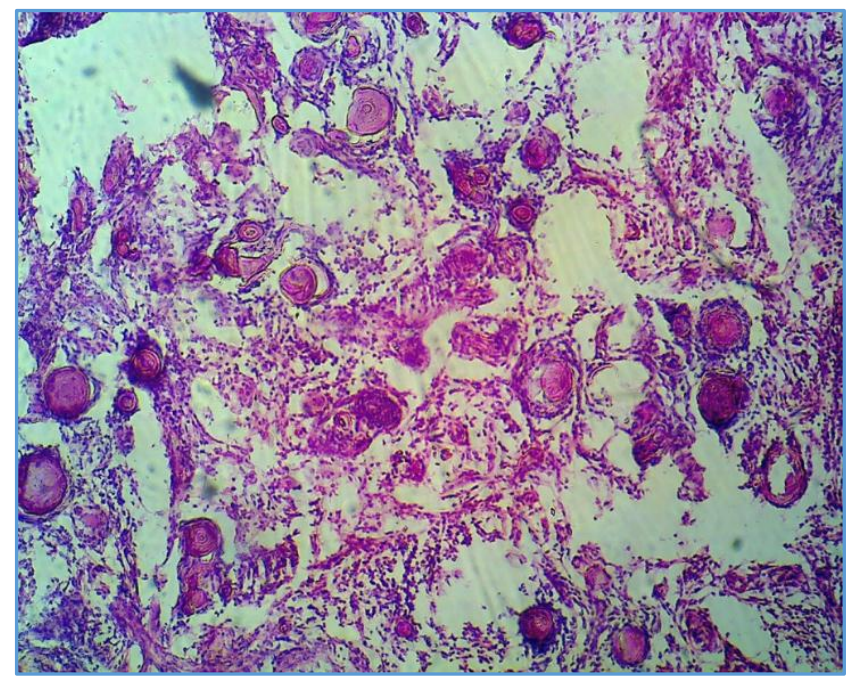

Figure 2. Meningioma

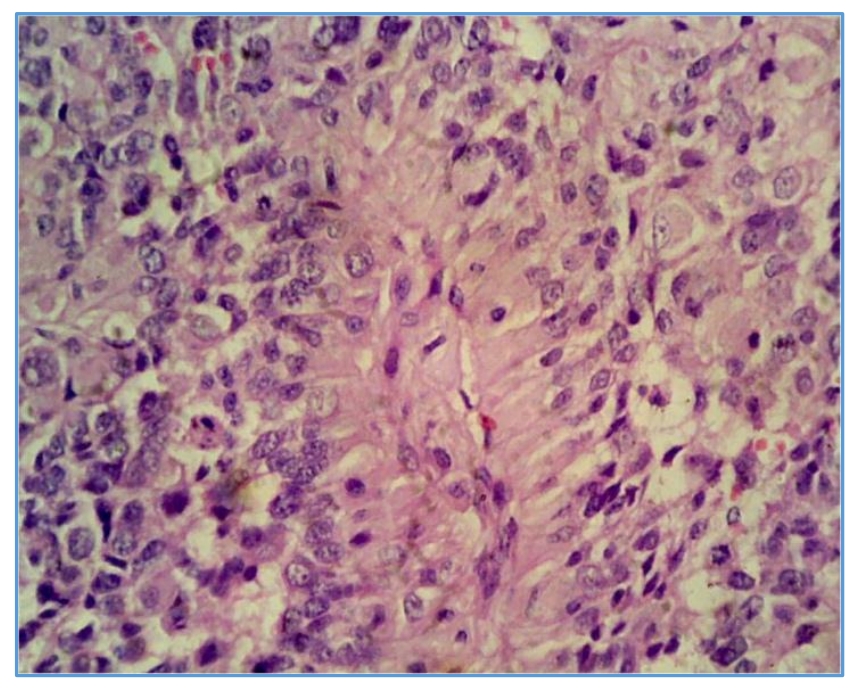

Figure 3. Ependymoma 


\begin{tabular}{|c|c|c|c|c|c|c|}
\hline Sl. No. & $\begin{array}{c}\text { Tumour Type } \\
\end{array}$ & WHO Grade & Male & Female & Total (\%) & Mean Age at Diagnosis \\
\hline A. & Tumours of Neuroepithelial Tissue & & & & & \\
\hline 1 & Astrocytic Tumours & & & & & \\
\hline $\mathrm{a}$ & Diffuse Astrocytoma & II & 22 & 10 & $32(8.1 \%)$ & 32.9 years \\
\hline $\mathrm{b}$ & Anaplastic Astrocytoma & III & 8 & 2 & $10(2.5 \%)$ & 36.2 years \\
\hline $\mathrm{c}$ & Glioblastoma & IV & 70 & 24 & $94(23.8 \%)$ & 49.8 years \\
\hline $\mathrm{d}$ & Gliosarcoma & IV & 4 & 0 & $4(1.0 \%)$ & 57.5 years \\
\hline 2 & Oligodendroglial Tumours & & & & & \\
\hline $\mathrm{a}$ & Oligodendroglioma & II & 12 & 0 & $12(3.0 \%)$ & 31.1 years \\
\hline $\mathrm{b}$ & Anaplastic oligodendroglioma & III & 10 & 0 & $10(2.5 \%)$ & 48.2 years \\
\hline 3 & Ependymal Tumours & & & & & \\
\hline $\mathrm{a}$ & Ependymoma & II & 8 & 4 & $12(3.0 \%)$ & 20 years \\
\hline $\mathrm{b}$ & Anaplastic ependymoma & III & 0 & 2 & $2(0.5 \%)$ & 16 years \\
\hline 4 & Choroid plexus tumours & & & & & \\
\hline $\mathrm{a}$ & Choroid plexus papilloma & I & 0 & 2 & $2(0.5 \%)$ & 58 years \\
\hline 5 & Neuronal and mixed neuronal-glial tumours & & & & & \\
\hline $\mathrm{a}$ & Gangliocytoma & I & 2 & 0 & $2(0.5 \%)$ & 28 years \\
\hline $\mathrm{b}$ & Ganglioglioma & I & 2 & 0 & $2(0.5 \%)$ & 21 years \\
\hline 6 & Embryonal tumours & & & & & \\
\hline $\mathrm{a}$ & Medulloblastoma & IV & 8 & 0 & $8(2.0 \%)$ & 8.2 years \\
\hline $\mathrm{b}$ & Peripheral Neuroectodermal tumour & IV & 2 & 2 & $4(1.0 \%)$ & 30.5 years \\
\hline B & Tumours of cranial and paraspinal nerves & & & & & \\
\hline 1 & Schwannoma & $\mathrm{I}$ & 22 & 8 & $30(7.6 \%)$ & 42.6 years \\
\hline 2 & Neurofibroma & $\mathrm{I}$ & 8 & 8 & $16(4.0 \%)$ & 36.6 years \\
\hline $\mathbf{C}$ & Tumours of meninges & & & & & \\
\hline 1 & Tumours of meningothelial cells & & & & & \\
\hline $\mathrm{a}$ & Meningioma & $\mathrm{I}$ & 46 & 56 & $102(25.8 \%)$ & 46.1 years \\
\hline $\mathrm{b}$ & Atypical Meningioma & II & 0 & 2 & $2(0.5 \%)$ & 27 years \\
\hline 2 & Mesenchymal Tumours & & & & & \\
\hline $\mathrm{a}$ & Lipoma & 0 & 2 & 0 & $2(0.5 \%)$ & 24 years \\
\hline $\mathrm{b}$ & Haemangioma & 0 & 2 & 0 & $2(0.5 \%)$ & 51 years \\
\hline c & Haemangiopericytoma & II & 2 & 2 & $4(1.0 \%)$ & 50.5 years \\
\hline 3 & Other neoplasms related to the meninges & & & & & \\
\hline $\mathrm{a}$ & Haemangioblastoma & I & 8 & 0 & $8(2.0 \%)$ & 33.7 years \\
\hline D & Tumours of Hematopoietic system & & & & & \\
\hline $\mathrm{a}$ & Malignant Lymphoma & III & 8 & 4 & $12(3.0 \%)$ & 48.5 years \\
\hline $\mathbf{E}$ & Tumours of Sellar region & & & & & \\
\hline $\mathrm{a}$ & Pituitary Adenoma & I & 2 & 0 & $2(0.5 \%)$ & 25 years \\
\hline $\mathbf{F}$ & Metastatic tumours & & 12 & 8 & $20(5.0 \%)$ & 43 years \\
\hline \multicolumn{7}{|c|}{ Table I. Distribution of CNS Tumours (as per WHO Classification 2007) } \\
\hline
\end{tabular}

WHO Grade is a parameter connected with the aggressiveness of the tumour. Grade 0 indicates benign tumour, Grade III and above are malignant tumours and Grade I indicates borderline tumour.

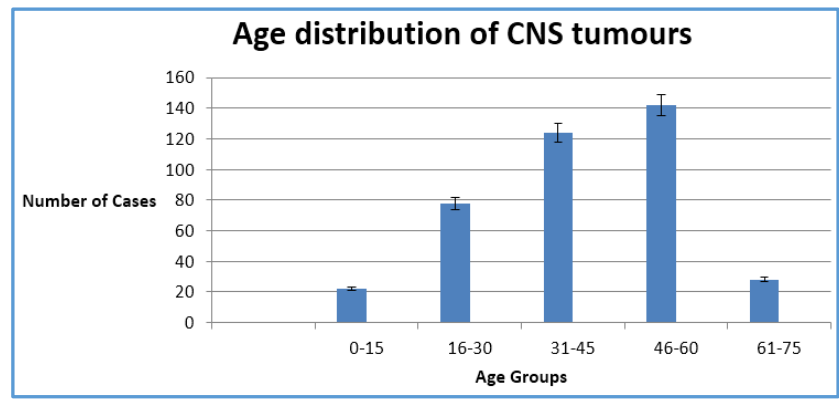

Figure 1. Age wise Distribution of CNS Tumours with Number of Cases

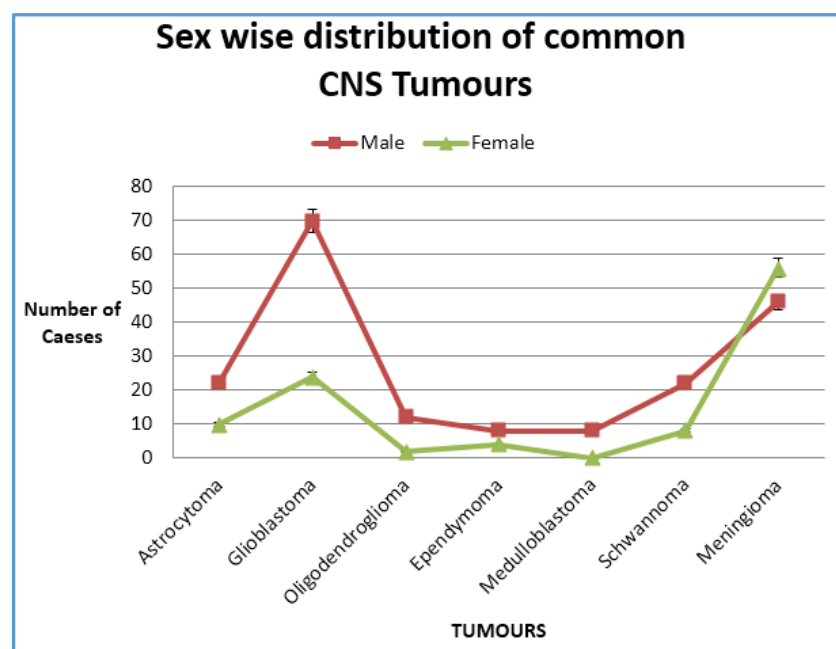

Figure 2. Sex wise Distribution of CNS Tumours with Number of Cases 


\section{DISCUSSION}

In developing countries like India, due to lack of complete registration of newly diagnosed cases with local cancer registries, the exact tumour burden goes unnoticed and is underestimated. Hospital-based prevalence data therefore forms the basis for estimating the disease load.

According to WHO 2007 classification, CNS tumours have been divided into six categories- tumours of neuroepithelial tissue, tumours of cranial and paraspinal nerves, tumours of meningothelial cells, tumours of hematopoietic system, tumours of sellar region and metastatic tumours. Gliomas are tumours of neuroepithelial tissue and are sub-classified as astrocytoma, oligodendroglioma and ependymoma depending on the cells of origin. They are the commonest CNS tumours globally accounting for approximately $70 \%$ of cases, with glioblastoma being the commonest subtype. ${ }^{5}$ In our series also, gliomas were the commonest tumour (44.7\%) followed by meningioma (26.4\%). Glioblastoma multiforme (GBM) composed (53.4\%) of all gliomas and (23.8\%) of all operated tumours. In a study done in Karachi by Bhurgri Y et al, gliomas accounted for $70 \%$ of all cases. ${ }^{6}$ In a study done in Punjab by Nibhoria $S$ et al, the most common CNS tumours in the descending order are tumours of neuroepithelial tissue (51.7\%) followed by tumours of meninges (34.8\%) and metastatic tumours (5.6\%). ${ }^{7}$ This was in concordance with the nationwide database in France which revealed the proportion of tumours of neuroepithelial tissue and the meninges as $53.9 \%$ and $28.8 \%$ respectively, from 2004 to $2008 . .^{8}$ Oligodendroglioma composed $5.5 \%$ of all tumours and $12.5 \%$ of all glial tumours. This collaborates with the statistics reported by El-Zein et al ${ }^{9}$ according to whom oligodendroglioma constitutes $5-12 \%$ of all glial tumours and $5-7 \%$ of all intracranial tumours. Ependymoma composed $3.5 \%$ in our series. This figure is slightly less than that reported $4-6 \%$ by El- Zein et al. Meningioma comprised (26.4\%) of all cases. This incidence is higher than $10-19 \%$ incidence reported by El-Zein et al. We did not observe striking predominance in females over males (Ratio 1.2:1) as reported by this group. In a study done by Ghanghoris $\mathrm{S}$ et $\mathrm{al}^{10}$ in Indore, meningioma was the most common tumour followed by astrocytoma. Out of total 65 cases, they came across 27 cases of meningioma, 16 cases of astrocytoma and 5 cases of ependymoma. Childhood tumours constituted a small group of 11 cases in our series (5.6\%). Among them, commonest was medulloblastoma (36\%), followed by astrocytoma (27\%) and ependymoma (27\%). This is consistent with the study done by Jain A et al, where the most common brain tumours in the paediatric age group in descending order were astrocytoma, medulloblastoma, craniopharyngioma followed closely by ependymoma. 11

A cause of concern is younger age of presentation of CNS tumours in our series. Peak incidence of CNS tumours in western countries occur at 65-79 years 12 whereas in our series, it was at 45-60 years. Mean age of presentation was 40.2 years and 44.8 years in studies conducted by Mehrazin et $\mathrm{al}^{13}$ in 2005 and Yavari $\mathrm{P}$ et al ${ }^{14}$ in 2006 respectively. A variation in mean age has been reported for each histological category 15 and for each of these categories the mean age observed in our series was also lesser. The mean age for meningioma is reported as 62 years ${ }^{13}$ whereas in our series it was 46.1 years. The mean age of low grade diffuse astrocytoma was 32.9 years, anaplastic astrocytoma was 36.2 years and glioblastoma was 49.8 years in our series, whereas the reported mean age is 34 years for low grade diffuse astrocytoma, 41 years for anaplastic astrocytoma and 53 years for glioblastoma. ${ }^{16}$

\section{CONCLUSION}

Central nervous tumours are not uncommon malignancies. They are aggressive tumours, and even better differentiated tumours have high morbidity and mortality. In our series, glioma was the commonest tumour followed by meningioma. A cause of concern is younger age of presentation of the tumours. Genetic and environmental factors may be responsible for our findings and further study is required to identify these factors.

\section{REFERENCES}

[1] Winn HR. Youmans neurological surgery. $6^{\text {th }}$ edn. Saunders/Elsevier 2011.

[2] Canadian Cancer Society's Steering Committee on Cancer Statistics, Toronto, ON: Canadian Cancer Society, Statistics Canada, 2011.

[3] Louis DN, Ohgaki H, Wiestler OD, et al. The 2007 WHO classification of tumours of the central nervous system. Acta Neuropathol 2007;114(2):97-109.

[4] Wrensch M, Minn Y, Chew T, et al. Epidemiology of primary brain tumors: current concepts and review of the literature. Neuro Oncol 2002;4(4):278-9.

[5] Ohgaki H. Epidemiology of brain tumors. Methods Mol Biol 2009;472:323-42.

[6] Bhurgri Y, Bhurgri H, Kayani N, et al. Trends and morphology of central nervous system malignancies in Karachi. Asian Pac J Cancer Prev 2011;12(8):2013-7.

[7] Nibhoria S, Tiwana KK, Phutela R, et al. Histopathological spectrum of central nervous system tumors: a single centre study of 100 cases. Int J Sci Stud 2015;3(6):130-4.

[8] Rigau V, Zouaoui S, Mathieu-Daudé H, et al. French brain tumor database: 5-year histological results on 25756 cases. Brain Pathol 2011;21(6):633-44.

[9] El-Zein R, Bondy M, Wrensch M. In: Osman FA. edr. Contemporary cancer research: brain tumours. Totowa, NJ: Humana Press Inc., 2010:1-18.

[10] Ghanghoria S, Mehar R, Kulkarni CV, et al. Retrospective histological analysis of CNS tumors-a 5 year study. Int J Med Sci Public Health 2014;3(10):1205-7.

[11] Jain A, Sharma MC, Suri V, et al. Spectrum of pediatric brain tumors in India: a multi-institutional study. Neurol India 2011;59(2):208-11.

[12] Chandana SR, Movva S, Arora M, et al. Primary brain tumours in adults. Am Fam Physician 2008;77(10):1423-30.

[13] Mehrazin M, Rahmat H. Epidemiology of primary intracranial tumours in Iran, 1978-2003. Asian Pac J Cancer 2006;7(2):283-8.

[14] Yavari P, Rahmat H. Epidemiology of primary intracranial tumours. Asian Pac J Cancer 2006:186-92.

[15] McCarthy BJ, Surawicz T, Bruner JM, et al. Consensus conference on brain tumor definition for registration. November 10, 2000. Neuro Oncol 2002;4(2):134-45.

[16] Kleihues P, Burger PC, Plate KH, et al. Glioblastoma. In: Kleihaus P, Canenee WK. eds. Pathology and Genetics: Tumours of the Nervous System. Lyon, France: International Agency for Research on Cancer 1997b. 